\title{
APLIKASI AGES REPLACEMENT METHODS DALAM MENENTUKAN OPTIMASI PENJADWALAN PERAWATAN KENDARAAAN
}

\author{
Ni Luh Putu hariastuti \\ Jurusan Teknik Industri \\ Institut Teknologi Adhi Tama Surabaya \\ putu_hrs@yahoo.com
}

\begin{abstract}
ABSTRAK
$\mathrm{A}$ danya mobilitas masyarakat yang dewasa ini cukup tinggi, menjadikan fenomena tersebut sebagai sebuah peluang bisnis yang menjanjikan. Namun harus diperhatikan juga terkait dengan fasilitas yang disediakan merupakan fasilitas yang mampu memberikan rasa aman dan nyaman bagi pihak pengguna. Disinilah diperlukan adanya jadwal perawatan fasilitas yang optimal sehingga fasilitas dalam hal ini adalah kendaraan dapat menjalankan fungsinya dengan baik, mengingat pengguna kendaraan (bus) adalah karyawan dengan sistem antar jemput setiap hari dan harus selalu tepat waktu.

Berdasarkan penelitian dengan menggunakan Metode Age Replacement diperoleh bahwa Interval perawatan pencegahan yang optimal yang dapat dilakukan perusahaan adalah setiap 10 hari dengan tingkat keandalan mesin atau relihabilitas sebesar $62,172 \%$. Sedangkan Waktu optimal perawatan pertahun dilakukan sebanyak 30 kali perawatan, dengan total biaya Rp. 1.340.175.743,31, lebih hemat sebesar 14,7\% dibandingkan dengAN kondisi riil.
\end{abstract}

Kata Kunci : Mobilitas, Jadwal Perawatan, Metode Age Replacement, Keandalan Mesin

\section{LATAR BELAKANG MASALAH}

Tingginya mobilitas masyarakat dewasa ini, membuat keberadaan sarana transportasi menjadi sangatlah penting. Hal ini menjadi salah satu peluang bisnis bagi usaha - usaha transportasi dalam menyediakan sarana penunjang yang sangat dibutuhkan dalam membantu proses mobilitas masyarakat pada umumnya

CV X, merupakan salah satu usaha bisnis yang bergerak dibidang transportasi, untuk mendukung usahannya, perusahaan didukung dengan beragam armada bus yang jumlahnya tidaklah sedikit dan tentunya biaya perawatan armada, khususnya perawatan mesin kendaraan menjadi suatu fokus utama perusahaan didalam meminimalkan biaya operasional

Mengingat pengguna bus adalah karyawan dengan sistem antar jemput setiap hari dan harus selalu tepat waktu dengan intensitas serta frekuensi penggunaan yang sangat tinggi, maka perencanaan penjadwalan perawatan mesin kendaraan untuk bus yang digunakan dalam antar jemput tersebut perlu diprioritaskan. Berdasarkan alasan-alasan tersebut maka biaya perawatan yang harus dikeluarkan perusahaan perlu diperhitungkan dengan sebaik- baiknya sehingga sangat perlu dilakukan penjadwalan perawatan kendaraan dalam rangka 44 minimalisasi biaya.

\section{PERUMUSAN MASALAH}

Berdasarkan latar belakang tersebut maka perumusan masalah dalam penelitian ini adalah : Bagaimanakah mengoptimalkan penjadwalan perawatan kendaraan sehingga dapat meminimalisasi biaya perawatan khususnya pada armada bus antar jemput karyawan?

\section{TUJUAN}

1. Merencanakan penjadwalan perawatan kendaraan khususnya pada bus antar jemput karyawan

2. Menentukankan waktu optimal untuk melakukan perencanaan perawatan

3. Menentukan prosentase penghematan yang dapat dihasilkan dari metode usulan.

\section{BATASAN MASALAH DAN ASUMSI}

Penyusun hanya membatasi pembahasan penelitian pada satu jenis kendaraan yaitu kendaraan angkutan karyawan dengan jenis Bus bermesin Mercy Of 1113, dan perhitungan hanya menyangkut : 1. Penggantian komponen mesin, 2. Perhitungan biaya perawatan, 3. Perhitungan biaya pemeliharaan pencegahan mencakup biaya tenaga kerja, biaya material/alat bantu perawatan 
Dan perusahaan yang menjadi obyek penelitian diasumsikan dalam kondisi yang normal

\section{MANFAAT}

Manfaat yang diharapkan dari penelitian ini adalah :

1. Dapat menjadi sumbangan pemikiran terhadap masalah-masalah yang dihadapi perusahaan terutama dalam pengaturan jadwal perawatan kendaraan.

2. Sebagai pertimbangan untuk melakukan perawatan berkala terhadap mesin kendaraan

3. Dengan berkurangnya biaya perawatan diharapkan dapat meminimalisasi biaya yang harus ditanggung oleh perusahaan secara keseluruhan serta memperlancar kegiatan operasional perusahaan dalam melayani jasa transportasi.

\section{LANDASAN TEORI}

\section{PERAWATAN}

Perawatan adalah "suatu kegiatan untuk memelihara atau menjaga agar fasilitas atau peralatan pabrik dan mengadakan perbaikan atau penggantian yang diperlukan agar supaya terdapat suatu keadaan operasi yang memuaskan sesuai dengan yang direncanakan. Secara garis besar, perawatan bertujuan untuk mencegah kerusakan pada sebuah mesin sehingga pada akhirnya dapat mengganggu proses produksi.

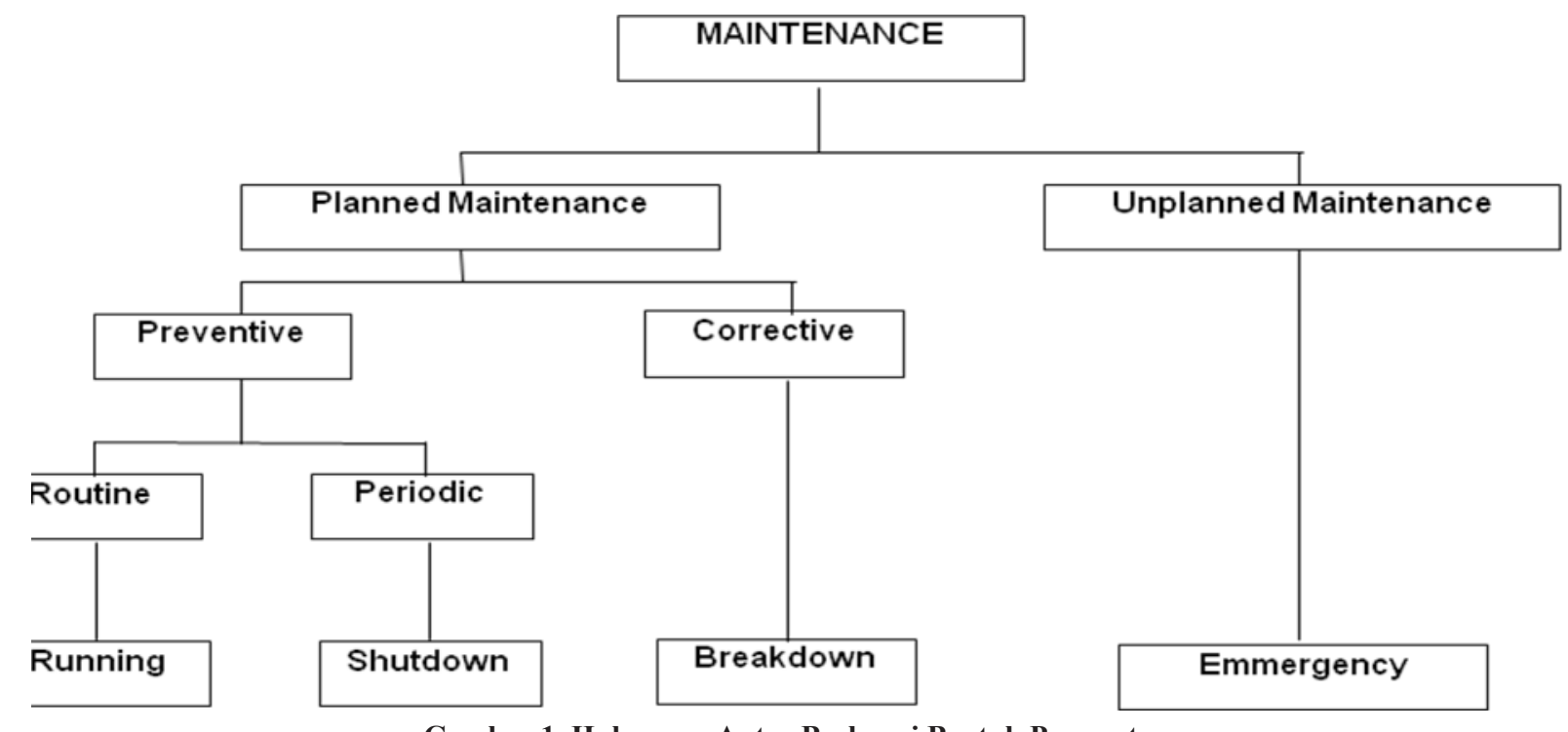

\section{LANGKAH -LANGKAH PENJADWALAN DENGAN MODEL AGE REPLACEMENT}

Langkah-langkah pengujian yang dilakukan berdasrkan atas metode pilihan adalah sebagai berikut :

Langkah 1. Data pengamatan dikelompokkan menjadi kelas-kelas dengan panjang terbatas.

Langkah 2. Menduga besarnya parameter $\mu$ dan $\sigma, \mu$ diduga mean sampel $\mathrm{x}$ dan $\sigma$ diduga dengan deviasi standart $\mathrm{s}$

$$
\begin{gathered}
\bar{x}=\frac{\sum \dot{x} \cdot F}{N} \\
s=\sqrt{\frac{\sum f i x i^{2}-\left(\frac{\sum f i x i}{N}\right)^{2}}{N-1}}
\end{gathered}
$$

Dimana :

$\begin{array}{lll} & = & \text { rata-rata sampel (dibaca } \mathrm{x} \text { garis) } \\ \mathrm{xi} & = & \text { titik tengah tiap kelas } \\ \mathrm{fi} & = & \text { frekuensi masing-masing kelas } \\ \mathrm{N} & = & \text { Jumlah pengamatan sampel } \\ \mathrm{S} & = & \text { deviasi standar sampel }\end{array}$

Langkah 3

Berdasarkan langkah 2, maka dapat dihitung nilai Ej dengan rumus :

Dimana :

$$
\mathrm{Ej}=\mathrm{N} \cdot \mathrm{Pj}
$$

sampel

$$
\begin{aligned}
& \mathrm{j}=1.2 . \ldots ., \mathrm{c} \\
& \mathrm{N}=\text { banyaknya pengamatan atau besar }
\end{aligned}
$$

$\mathrm{Ej}=$ menyatakan harapan banyaknya pengamatan dalam kelas jika hipotesa Ho benar. langkah 4.

Melakukan uji statistik dengan rumus sebagai berikut : 


$$
\sum_{j=1}^{c} \frac{(O-E)^{2}}{F}
$$

$\mathrm{x}^{2} \mathrm{Uji}=$

1.Uji mempunyai derajat kebebasan $\mathrm{v}=(\mathrm{c}-1-\mathrm{k})$, dimana $\mathrm{k}$ adalah banyaknya parameter

2. Yang tidak diketahui. Parameter tersebut yaitu $\mu$ dan $\sigma$. Keputusan $\mathrm{Ho}$ diterima bila $\mathrm{x} 2 \mathrm{uji}<\mathrm{x} 2$ tabel

\section{Menentukan Distribusi Kerusakan}

Untuk masalah perawatan ini, dipilih distribusi normal dengan alasan bahwa waktu antar kerusakan merupakan variabel acak. Untuk mengetahui bahwa pola distribusi kerusakan normal, maka digunakan pengujian kecocokan distribusi dengan menggunakan Uji-Chi Square Goodnees of Fit

Langkah-langkah pengujian tersebut dilakukan sebagai berikut:

Langkah 1Data pengamatan dikelompokkan menjadi kelas-kelas dengan panjang tertentu.

Langkah 2Menduga besarnya parameter $\mu$ dan $\sigma . \mu$ diduga dengan sampel dan $\sigma$ diduga dengan deviasi standard $\mathrm{S}$

Dimana:

$\mathrm{S}=$ deviasi standart sampel

$\mathrm{xi}=$ titik tengah tiap kelas

$\mathrm{fi}=$ frekuensi masing-masing kelas
Langkah 3

$\mathrm{N}=$ jumlah pengamatan sampel

Berdasarkan langkah 2, dihitung Ej dengan rumus:

$E j=N . P j$

Dimana: $\mathrm{j} \quad=1,2,3, \ldots \ldots \mathrm{n}$

$\mathrm{N} \quad=$ banyaknya pengamatan

$\mathrm{Ej} \quad=$ harapan banyaknya pengamatan

dalam kelas jika hipotesis Ho benar.

$\mathrm{Pj}=$ probabilitas pengamatan

Langkah 4

Melakukan uji statistik dengan rumus sebagai berikut:

$$
\mathrm{X} 2 u \mathrm{uji}=\sum_{j=1}^{c} \frac{\left(O_{j}-E_{j}\right)^{2}}{E j}
$$

Dimana:

$\mathrm{Ej} \quad=$ harapan banyaknya pengamatan dalam

kelas jika Ho benar

$\mathrm{Oj} \quad$ = frekuensi banyaknya pengamatan

$\mathrm{X} 2$ uji mempunyai derajat kebebasan sebesar $\mathrm{v}$ $=(\mathrm{c}-1-\mathrm{k})$, dimana $\mathrm{k}$ adalah parameter yang tidak diketahui yaitu $\mu$ dan $\sigma$.Keputusan Ho diterima bila $\mathrm{X} 2 \mathrm{uji}<$ Xtabel

\section{METODOLOGI PENELITIAN}

Adapun langkah penelitian dapat diberikan dalam gambar flowchart sebagai berikut :

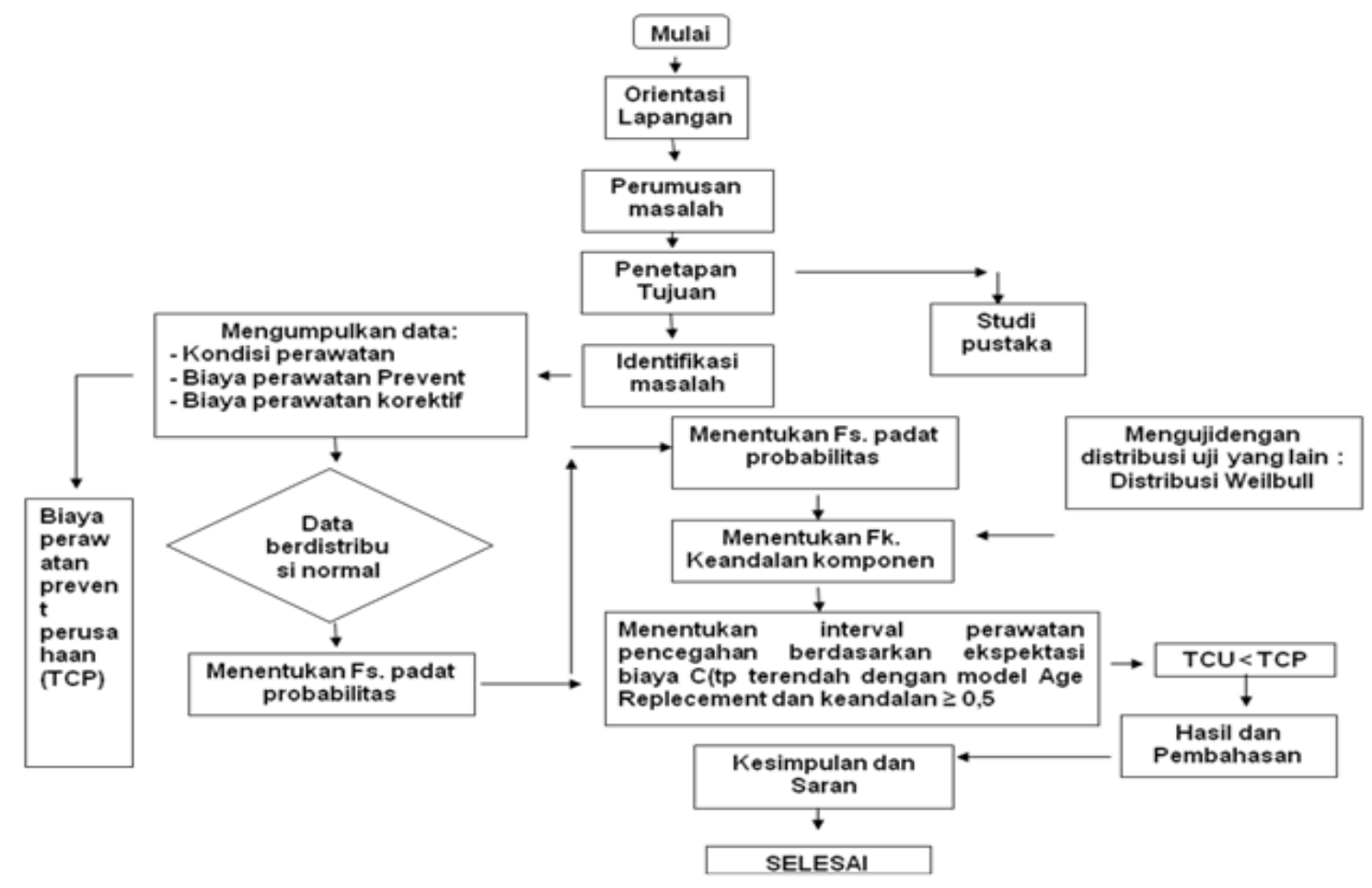

Gambar .2 Metodologi Penelitian 


\section{HASIL DAN ANALISA}

CV X adalah perusahaan yang bergerak dibidang jasa angkutan Wisata dan karyawan, perusahaan ini berdiri sejak tahun 1985.Adapun Armada - armada yang dimiliki perusahaan adalah Bus AC dengan kapasitas 33,40,54,56,dan 59 seats sedangkan Bus non AC dengan kapasitas 27,29,49 \& 59 seats dengan merek Bus Mercy \& Hino Untuk perawatan armada bus itu sendiri perusahaan mempunyai bengkel dengan tenaga ahli dibidangnya.

Proses pengolahan data dilakukan dengan dengan menggunakan metode Age Replacement, yaitu metode perawatan pencegahan yang dilakukan dengan menetapkan interval waktu perawatan pencegahan berdasarkan selang waktu kerusakan yang menuntut adanya tindakan perbaikan penggantian dengan kriteria minimalisasi.

Tabel 1 Pengelompokan kelas dan frekuensi waktu antar kerusakan

\begin{tabular}{|c|c|c|c|c|}
\hline Kelas & Titik tengah & Frekuensi & f.x & $\mathrm{fx}^{2}$ \\
\hline $3-5$ & 4 & 4 & 16 & 64 \\
\hline $6-8$ & 7 & 5 & 35 & 245 \\
\hline $9-11$ & 10 & 4 & 40 & 400 \\
\hline $12-14$ & 13 & 5 & 65 & 845 \\
\hline $15-17$ & 16 & 5 & 80 & 1280 \\
\hline $18-20$ & 19 & 4 & 76 & 1444 \\
\hline Jumlah & & 27 & 312 & 4278 \\
\hline
\end{tabular}
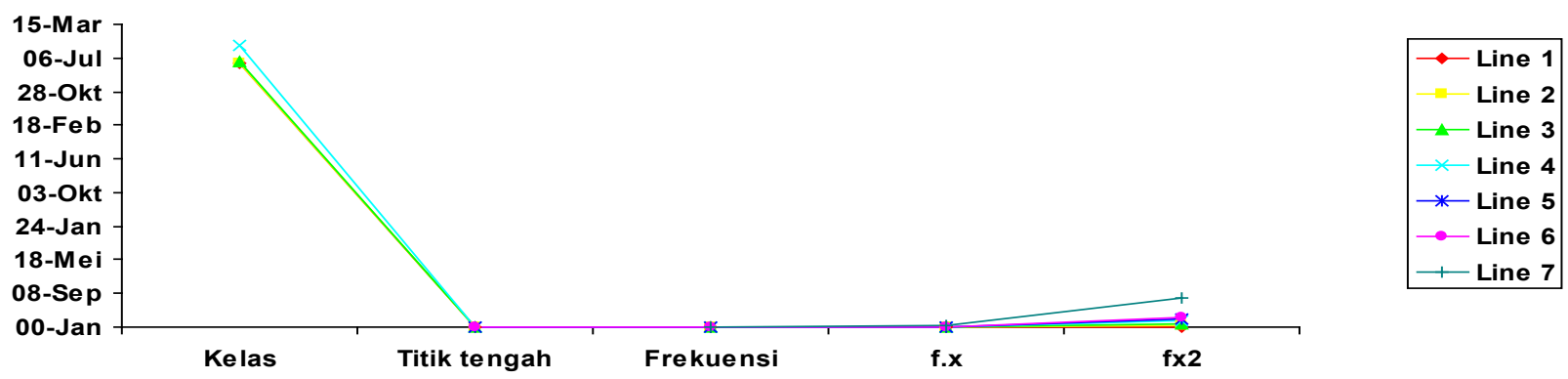

Gambar .3 Grafik Frekuensi Waktu Antar Kerusakan yang Terjadi

Berdasarkan atas data yang ada, maka dapat dihitung fungsi padat probabilitas yang terjadi sebagai dasar perhitungan waktu pergantian mesin, dengan perhitungan sebagai berikut :

$F(t p)=\frac{1}{\sigma \sqrt{2 \pi}} \exp \cdot\left[\frac{-(t p-\mu)^{2}}{2 \sigma^{2}}\right]$

$\bar{x}=11,56$

dan $\mathrm{S}=5,09$ atau dapat

disimpulkan $=11,56$ dan $=5,09$ sedangkan tp $=1$ hari

$F(|+|)=\frac{1}{5,09 \sqrt{2 \times 3,14}} \exp \left[\frac{-(1-11,56)^{2}}{2(5,09)^{2}}\right]$

$$
\begin{aligned}
= & \frac{1}{12,7466} \exp \cdot\left[\frac{-111,4198}{51,7436}\right] \\
& =0,0785 \exp \cdot(-2,1533) \\
& =0,00911
\end{aligned}
$$

Menentukan Tingkat Keandalan Komponen

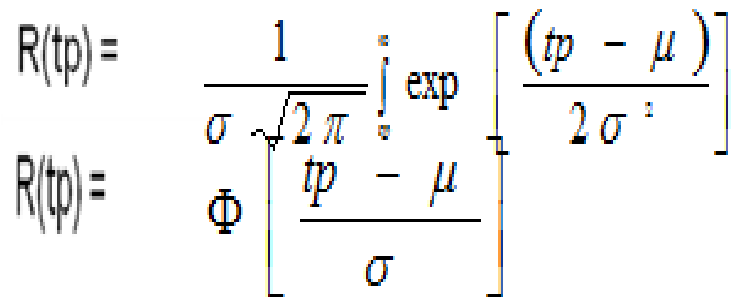

Dimana : (tp)dapat dilihat pada tabel standart distribusi normal. 


$$
\begin{aligned}
R(t p) & =1-\Phi\left[\frac{1-11,56}{5,09}\right] \\
& =1-\Phi(-2,08) \\
& =1-0,01876 \\
& =0,98124
\end{aligned}
$$

Biaya - biaya pendukung terkait dengan Biaya perbaikan kerusakan diberikan oleh perusahaan sebagai berikut :

- Pemeliharaan pencegahan dilakukan selama : 3 jam

- Biaya tenaga kerja : Rp 15.000/Hari

- Waktu kerja : $8 \mathrm{Jam} /$ Hari

- Jumlah tenaga kerja mekanik : 3 orang

- Perbaikan kerusakan mesin mercy Seperti : oli, air accu, filter oli, dll, ditetapkan sebesar Rp 20.045.000,00 /bulan

- Kerugian yang ditanggung perusahaan jika bus harus terhenti, diperkirakan sebesar : Rp 7.500.000 per jamnya

Berdasarkan atas biaya - biaya yang ada, maka dapatlah dihitung besarnya Biaya Perawatan yang terjadi, yaitu:

Untuk total biaya pemeliharaan dapat dihitung dengan rumus :

$$
\mathrm{C}(\mathrm{tp})=\frac{C p x R(t p)+C f[1-R(t p)]}{t p x R(t p)+\int_{-\infty}^{t} t f(t) d t}
$$

Contoh perhitungan :Bila tp $=1$, maka

$$
\begin{aligned}
& C(1)=\frac{(R p .22 .635 .625 \times 0.98124)+R p .50 .067 .500(1-0,98124)}{(1 \times 0.98124)+(-0.01669)} \\
= & \text { Rp. } 24.000 .951,97 \\
& \text { Jadi (C1)/ Tc }=\text { Rp 24.000.951,97 }
\end{aligned}
$$

Dengan cara yang sama, maka dapat dilakukan perhitungan untuk jumlah tp (lama waktu perbaikan/ perawatan) yang bervariasi sehingga dapat ditemukan waktu perawatan yang paling optimal.

Dari perhitungan yang telah dilakukan maka besarnya biaya perawatan yang terjadi dapat dinyatakan dalam grafik yang mencerminkan hubungan antara waktu perbaikan dengan besarnya biaya perawatan. Adapun grafik tersebut dinyatakan dalam gambar 4 dibawah ini.

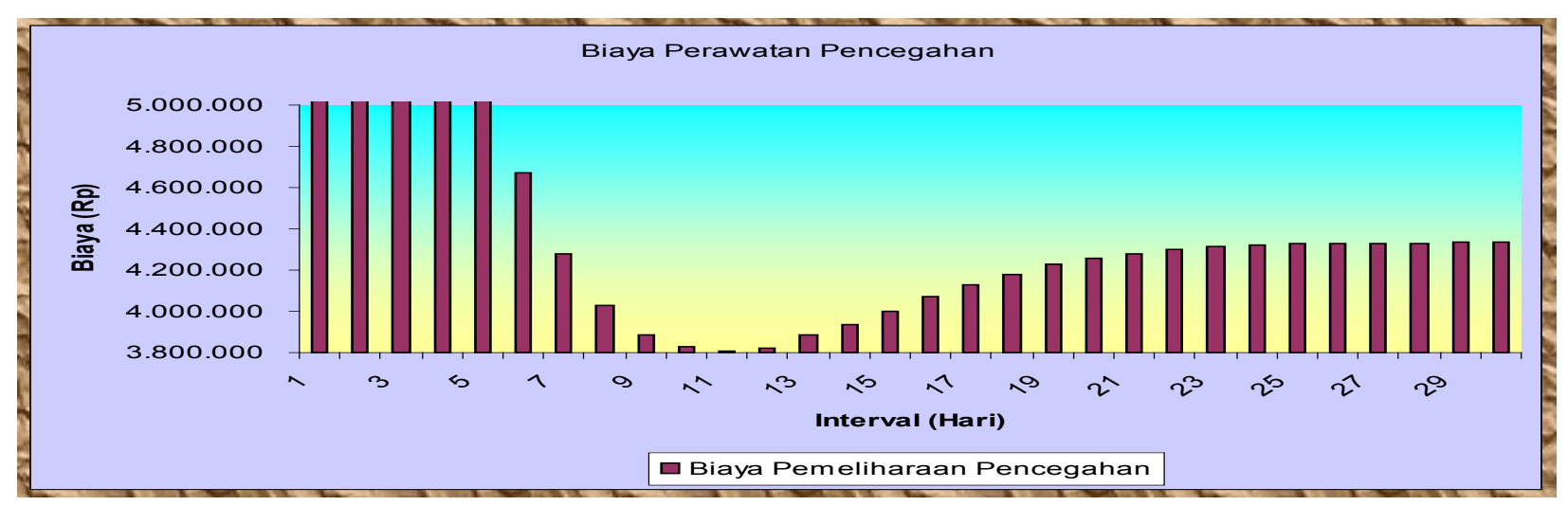

Gambar 4. Grafik Total Cost Pemeliharaan Pencegahan

Gambar diatas menunjukkan total cost perawatan yang tinggi pada interval setiap 1 hari yang kemudian cenderung menurun (dari interval setiap 1 hari sampai dengan interval 5 hari masih di atas Rp. 5.000.000.) Namun kemudian setelah interval 11 hari total cost perawatan secara bertahap cenderung mengalami kenaikan.

Dengan pertimbangan tingkat reliabilitas mesin yang ditetapkan adalah di atas 60\% maka akhirnya diperoleh bahwa cost perawatan pecegahan yang optimal adalah sebesar Rp 3.814.441,44. pada interval setiap hari ke 10 .

\section{KESIMPULAN DAN SARAN}

Berdasarkan analisa dan pembahasan yang telah dilakukan, maka dapat ditarik kesimpulan sebagai berikut

1. Interval perawatan pencegahan yang optimal untuk kegiatan pemeliharaan mesin Mercy Of 1113 adalah setiap 10 hari dengan tingkat keandalan mesin atau reliabilitas sebesar 0,62172 atau $62,172 \%$.

2. Waktu yang optimal untuk melakukan perawatan dalam setahun adalah sebanyak 30 kali perawatan. Dengan memperhitungkan biaya kerugian karena terhentinya kendaraan 
angkutan karyawan maka dalam satu tahun total biaya perawatan pencegahan yang timbul adalah sebesar Rp. 789.433.243,31.

3. Dengan jumlah biaya pemeliharaan metode perusahaan sebesar Rp. 1.572.458.125,00 dan jumlah biaya pemeliharaan usulan sebesar Rp. 1.340.175.743,31, maka jumlah biaya pemeliharaan bila menggunakan metode usulan dalam satu tahun periode adalah sebesar Rp. 232.282.381,69 atau $14,7 \%$

\section{SARAN}

Saran yang dapat diberikan berdasarkan hasil penelitian adalah perusahaan diharapkan melakukan pemeliharaan sebelum tingkat keandalan (reliabilitas) mesin dibawah $60 \%$ untuk menghindari kerugian yang besar karena terjadinya jumlah kerusakan yang cukup besar.

\section{DAFTAR PUSTAKA}

Johannes H.J G, Optimal Age Replacement versus Condition Based Replacement, Journal of Quality Technology Vol.15, No 4 Oktober 1983

Shey-Huei Sheu, Optimal Age-Replacement Policy With Age-Dependent Minimal Repair and Random Leadtime, IEE Reliability Society, 2001 